\title{
Comparative study of bronchial artery revascularization in lung transplantation
}

\author{
Gösta B. Pettersson, MD, PhD, ${ }^{a}$ Karam Karam, MD, ${ }^{a}$ Lucy Thuita, MS, ${ }^{\mathrm{b}}$ Douglas R. Johnston, MD, ${ }^{\mathrm{a}}$ \\ Kenneth R. McCurry, MD, ${ }^{a}$ Samir R. Kapadia, MD, ${ }^{c}$ Marie M. Budev, DO, MPH, ${ }^{\mathrm{d}}$ Robin K. Avery, MD, \\ David P. Mason, MD, ${ }^{a}$ Sudish C. Murthy, MD, PhD, ${ }^{a}$ and Eugene H. Blackstone, $\mathrm{MD}^{\mathrm{a}, \mathrm{b}}$
}

Objective: Restoring dual blood supply to transplanted lungs by bronchial artery revascularization (BAR) remains controversial. We compared outcomes after lung transplantation performed with and without BAR.

\begin{abstract}
Methods: From December 2007 to July 2010, 283 patients underwent transplantation; 187 were 18 years or older, without previous or concomitant cardiac surgery. Of these patients, 27 underwent BAR in a pilot study to test success, safety, effectiveness, and teachability. A propensity score was generated to match BAR patients and 54 routine non-BAR patients. Follow-up was $1.3 \pm 0.68$ years.
\end{abstract}

\begin{abstract}
Results: BAR was angiographically successful in 26 (96\%) of 27 patients. BAR and non-BAR patients had similar skin-to-skin time $(P=.07)$ and postoperative hospital stays $(P=.2)$, but more reoperations for bleeding $(P=.002)$. Tracheostomy was performed in $9(33 \%)$ of 27 BAR and $10(19 \%)$ of 54 non-BAR patients $(P=.2$, log-rank). One BAR $(3.7 \%)$ and 4 non-BAR $(7.4 \%)$ patients required extracorporeal membrane oxygenation $(P=.7)$. Airway ischemia was observed in 1 BAR $(3.7 \%)$ versus 12 non-BAR $(22 \%)$ patients $(P=.03)$; anastomotic intervention was required in no BAR versus 8 non-BAR $(15 \%)$ patients $(P=.04)$. Hospital mortality was 1 of 27 versus 2 of $54(P=.9)$. BAR patients had lower early biopsy tissue rejection grades $(P=.008)$ and fewer pulmonary $(P<.04)$ and bloodstream $(P<.02)$ infections. Forced 1-second expiratory volume was similar $(P>.2) ; 3$ BAR versus 9 non-BAR patients developed bronchiolitis obliterans syndrome (BOS) $(P=.14$, log-rank). During follow-up, 4 BAR and 8 non-BAR patients died $(P=.6, \log$-rank $)$.
\end{abstract}

Conclusions: BAR is safe, with comparable early outcomes. Benefits of BAR include reduced airway ischemia and complications, lower biopsy tissue grades, fewer infections, and delay of BOS. A multicenter study is needed to establish these benefits. (J Thorac Cardiovasc Surg 2013;146:894-900)

Video clip is available online.

\section{Vide}

From the Department of Thoracic and Cardiovascular Surgery, ${ }^{\mathrm{a}}$ Heart and Vascular Institute; the Department of Quantitative Health Sciences, ${ }^{\text {b }}$ Research Institute; the Department of Cardiovascular Medicine, ${ }^{\mathrm{c}}$ Medicine Institute; the Department of Pulmonary, Allergy, and Critical Care Medicine, ${ }^{\mathrm{d}}$ Respiratory Institute, Cleveland Clinic, Cleveland, Ohio; and the Division of Infectious Disease (Transplant/ Oncology), ${ }^{\mathrm{e}}$ Johns Hopkins, Baltimore, Md.

This study was supported, in part, by the Peter and Elizabeth C. Tower and Family Endowed Chair in Cardiothoracic Research, James and Sharon Kennedy, the Slosburg Family Charitable Trust, Stephen and Saundra Spencer, and Martin Nielsen (to Dr Pettersson), and the Kenneth Gee and Paula Shaw, PhD, Chair in Heart Research (to Dr Blackstone).

Disclosures: Authors have nothing to disclose with regard to commercial support.

Received for publication Aug 2, 2012; revisions received March 22, 2013; accepted for publication April 18, 2013; available ahead of print July 1, 2013.

Address for reprints: Gösta B. Pettersson, MD, PhD, Department of Thoracic and Cardiovascular Surgery, Cleveland Clinic, 9500 Euclid Ave, Mail Stop J4-1, Cleveland, OH 44195 (E-mail: petterg@ @cf.org).

$0022-5223 / \$ 36.00$

Copyright (c) 2013 by The American Association for Thoracic Surgery

http://dx.doi.org/10.1016/j.jtcvs.2013.04.030
Supplemental material is available online.

Outcomes after lung transplantation remain worse than those after heart, liver, or kidney transplantation. The 2 main causes of death are infections and obliterative bronchiolitis (OB), small airway fibrosis resulting in progressive loss of lung function. ${ }^{1}$ After establishing OB as a manifestation of chronic rejection, recent research has focused attention on airway ischemia as a probable important cause. ${ }^{2}$ Normal lungs have a dual blood supply, but routine lung transplantation does not include restoring bronchial artery blood supply. The technique of bronchial artery revascularization (BAR) is well described and has been successful in small series. ${ }^{3-5}$ The largest series of en bloc double-lung transplants with BAR, from Copenhagen, Denmark, demonstrated excellent success and long-term survival, superior to the more recent series of sequential bilateral non-BAR lung transplants from the same institution. ${ }^{6,7}$

These favorable long-term outcomes reported from Copenhagen inspired the Cleveland Clinic (Cleveland, Ohio) lung transplant group to revisit BAR. A pilot study to confirm 

Abbreviations and Acronyms
BAR = bronchial artery revascularization
BOS = bronchiolitis obliterans syndrome
$\mathrm{CL}=$ confidence limit
$\mathrm{CPB}=$ cardiopulmonary bypass
FEV1 = forced 1-second expiratory volume
FEV $1 \%=\%$ of predicted FEV 1
IRB = Institutional Review Board
$\mathrm{OB}=$ obliterative bronchiolitis
PGD = primary graft dysfunction

the procedure's success, safety, and clinical effectiveness, and to prove teachability, was initiated in December 2007. Halfway into the study, we have compared outcomes after BAR with those after routine non-BAR lung transplantation.

\section{METHODS}

\section{Patients}

From December 1, 2007, to July 1, 2010, 283 lung transplantations (3 liver/lung, 6 heart/lung, and 274 lung only) were performed at Cleveland Clinic; 187 were lung transplant only in patients 18 years or older without previous or concomitant cardiac surgery. Of these, 20 (74\%) double-lung and $7(26 \%)$ single-lung transplants were performed with BAR and 160 without BAR (Table E1).

BAR operations were performed as an Institutional Review Board (IRB)-approved pilot study, with separate patient consent required for the angiogram to verify BAR patency, and Data and Safety Monitoring Board adjudication of adverse events. The IRB stipulated that one surgeon (G.B.P.) perform the first $25 \mathrm{BAR}$ lung transplants to demonstrate results equivalent to his Copenhagen experience, ${ }^{5,6}$ then teach other surgeons to perform the procedure on the subsequent 25 .

During the pilot, all lung transplant recipients are being approached, and most have consented for BAR. However, transplants performed when G.B.P. is unavailable are not permitted to be done with BAR. For single-lung transplants, bronchial anatomy allows BAR for both lungs in less than $50 \%$ of cases. Dividing the donor block requires experience identifying bronchial arteries, and we are not confident at this stage to do this at the donor hospital. This limits BAR for single-lung transplantation to blocks brought back undivided. In addition, occasionally, anatomy and arterial sclerosis in the donor aorta preclude ability to perform BAR.

\section{Study Design}

Because the IRB did not permit a randomized trial to be performed, but only a pilot study to demonstrate proficiency and safety, we performed a propensity-matched comparison of outcomes with contemporaneous routine non-BAR lung transplantation. ${ }^{8}$

\section{Surgical Techniques}

Donor lungs for BAR are procured en bloc with the esophagus and descending aorta to secure inclusion of the retroesophageal right intercostobronchial artery. Lung transplants with BAR are performed according to techniques previously described. ${ }^{9-15}$ One internal thoracic artery is harvested. Double-lung transplantation is performed en bloc via sternotomy using cardiopulmonary bypass (CPB) with tracheal anastomosis. For en bloc transplants, the BAR anastomoses are performed first, followed by the trachea, pulmonary trunk, and left atrium anastomoses. The internal thoracic artery is anastomosed to 1 or more bronchial artery ostia in the donor descending aorta. For single-lung transplantation, which is not performed on $\mathrm{CPB}$, the bronchial anastomosis is performed at the secondary carina, as in non-BAR transplants. The BAR anastomosis is performed last, after giving 10,000 IU heparin and after pulmonary artery reperfusion.

In this pilot study, transplants without BAR are performed by established techniques as sequential bilateral or single-lung transplants. The donor bronchus is divided immediately proximal to the secondary carina, and anastomosis is performed with a nonresorbable monofilament suture, running or interrupted, without intent to telescope one end into the other. $\mathrm{CPB}$ is used as needed or according to surgeon preference.

\section{End Points}

Procedure success. Visualization of any bronchial arteries after selective contrast injection into the internal thoracic artery conduit was considered successful BAR. Although noninvasive imaging has successfully identified bronchial artery patency in most instances, it remains imperfect. ${ }^{16}$ Thus, in this pilot study, direct angiography is required by the Institutional Review Board.

Safety. Variables related to safety of BAR included CPB time, skin-toskin operative time, reoperation for bleeding, intensive care unit and postoperative lengths of stay, requirement for tracheostomy, posttransplant extracorporeal membrane oxygenation support, and hospital mortality.

Clinical effectiveness. Clinical effectiveness was assessed by evidence of airway ischemia and airway interventions, lung biopsy tissues for rejection grade, primary graft dysfunction (PGD) grade, serious infections, forced 1 -second expiratory volume (FEV1) normalized to $\%$ of predicted (FEV1\%), bronchiolitis obliterans syndrome (BOS), and intermediate-term survival.

Evidence of airway issues, possibly related to ischemia, was abstracted from each bronchoscopy laboratory report and review of images to confirm positive findings. Findings of avascular mucosa, mucosal sloughing, necrosis, ulcer, anastomotic dehiscence, or late airway stenosis were considered potentially related to airway ischemia. Airway intervention was recorded separately.

Posttransplant routine lung biopsy specimens were graded according to the Lung Rejection Study Group classification system. ${ }^{17}$ For this study, we focused on perivascular rejection grades A0 through A4. The number of biopsy specimens available across time is depicted in Figure E1, A. Based on this distribution, we reliably estimated the prevalence of each grade up to 1.25 years posttransplant.

PGD was graded according to The International Society for Heart and Lung Transplantation guidelines. ${ }^{18}$ All patients had PGD data available at $0,24,48$, and 72 hours after transplant.

All infections occurring within 1 year in all lung transplant patients were reviewed, adjudicated, and categorized in a completely blinded manner by an infectious disease physician (R.K.A.). The same infection prophylaxis was used in BAR and non-BAR patients.

Results of all spirometry assessments performed in the Cleveland Clinic's certified pulmonary function laboratory, which conforms to the standards of the American Thoracic Society, were retrieved from the Pulmonary Function Test database. These included National Health and Nutrition Examination Survey-normalized postoperative FEV1\%, ${ }^{19,20}$ which was the primary variable analyzed. The number of pulmonary function tests available for analysis across time is shown in Figure E1, B. BOS was defined and graded by reduction in FEV1\%. ${ }^{21}$ Data related to BOS were reviewed, adjudicated, and graded by an experienced pulmonologist (M.M.B.) and include pre-BOS.

Survival was ascertained by annual anniversary follow-up as of March 31, 2011. No patient was lost to follow-up. The mean follow-up time among survivors was $1.3 \pm 0.68$ years (median, 1.06 years); $10 \%$ were followed up for more than 2.1 years.

\section{Data}

Data were retrieved from the Electronic Data Interface for Transplant database, the Cardiovascular Information Registry, and the Pulmonary 
Function Laboratory database. Supplemental information was obtained from medical record review. Use of these data for research was approved by the Cleveland Clinic Institutional Review Board, with patient consent waived.

\section{Data Analysis \\ Propensity score matching. Multivariable logistic regression was performed to identify preoperative factors associated with 27 BAR patients versus 160 non-BAR patients, considering variables listed in Appendix E1. Initially, a parsimonious model was developed using bagging with auto- mated analysis of 500 resampled data sets for variable selection at $P \leq$ $.05{ }^{22,23}$ BAR patients had a longer wait list time $(P=.0005)$, but were less likely to have chronic obstructive pulmonary disease, emphysema, or $\alpha-1$ antitrypsin deficiency $(P=.003)$. \\ We augmented this model with additional prespecified patient factors noted in Appendix E1, regardless of their statistical significance $(\mathrm{C}$-statistic $=.81)$. By using the resulting propensity model, we calcu- lated a propensity score for each patient, which was used in nearest- neighbor matching with replacement (bootstrap strategy) of 1 BAR patient to 2 non-BAR patients. Patients were well matched, as demon- strated by standardized differences before and after matching (Table 1 and Figure E2).}

Safety. Categorical variables are summarized by frequencies and percentages, with comparisons made using the $\chi^{2}$ or Fisher exact test. Continuous variables are summarized as mean and $\mathrm{SD}$, or equivalent median and 15 th and 85th percentiles for skewed variables. Continuous variables were compared using the Wilcoxon rank-sum test. For consistency, $68 \%$ confidence limits (CLs) or bands are used, equivalent to $\pm 1 \mathrm{SE}$.

Tracheostomy was treated as a time-related event assessed nonparametrically by the Kaplan-Meier method. BAR and non-BAR estimates were compared using the log-rank test. These methods were used for all timerelated events.

Clinical effectiveness. Airway ischemia at bronchoscopy and airway interventions were treated as time-related events.

Lung biopsy specimen rejection data were analyzed as a longitudinal repeated-measures ordinal variable. Time from transplant to biopsy ranged from 0 to 2.9 years (median, 3.8 months). Because of sparse data, grades A2 and $\mathrm{A} 3$ were combined into 1 group (grade $\mathrm{A} 2+$ ). Consequently, an ordinal scale of 3 grades was analyzed: $0, \mathrm{~A} 1$, and $\mathrm{A} 2+$. No patient in the study cohort had biopsy tissue grade A4. A multiphase nonlinear cumulative logit mixed model (SAS PROC NLMIXED; SAS Institute, Inc, Cary, NC) was used to resolve several time phases (temporal decomposition), estimate the shaping parameters of each phase, and determine the temporal trend of the patient-specific prevalence of each biopsy tissue grade over time, ${ }^{24}$ assuming a multinomial distribution. To determine the effect of BAR, we forced the group variable into each phase of the model.

Pulmonary, bloodstream, and overall infections were analyzed as possibly repeating events using the method of Nelson, ${ }^{25}$ with comparison by the log-rank test.

PGD scores were analyzed in the same manner as described for lung biopsy specimens, but at 4 points: immediately after transplant and after 24, 48 , and 72 hours.

Postoperative lung function was evaluated using FEV1 ( $\%$ of predicted). At least 1 spirometry measurement was made after transplant for $25(93 \%)$ BAR patients and $48(89 \%)$ non-BAR patients. Overall, 727 spirometry assessments were analyzed (243 in BAR and 484 in nonBAR patients). The median collection time of FEV1 was 0.44 years (range, 13 days to 2.9 years) (Figure E1, B). Based on the distribution of spirometry examinations, we reliably estimated average FEV1 ( $\%$ of predicted) up to 1.5 years posttransplant. The continuous repeated measurements of FEV1 were analyzed longitudinally across time, similar to the biopsy data.

Because of few occurrences of BOS, all grades, including pre-BOS, were considered together as a binary outcome. It was analyzed as a longitudinal cross-sectional outcome, an interval-censored outcome, and a single time-related event. All analyses yielded consistent estimates; thus, simple Kaplan-Meier estimates are depicted, with several different tests of differences between BAR and non-BAR patients made. Survival was estimated nonparametrically by the Kaplan-Meier method.

\section{RESULTS \\ Procedure Success}

Angiography demonstrated patent BAR in 24 of the 25 patients in whom the internal thoracic artery was injected (Video 1). One patient (with normal airway healing) refused the imaging study, and another died 6 weeks after transplantation and before imaging; autopsy demonstrated patent BAR and a normally healing airway.

\section{Safety}

BAR and non-BAR patients had similar CPB (relevant for double-lung transplants: $164 \pm 32[\mathrm{n}=20]$ vs $178 \pm$ $78[\mathrm{n}=37]$ minutes; $P=.3)$ and skin-to-skin $(350 \pm 71$ vs $318 \pm 86$ minutes; $P=.07)$ times, and postoperative intensive care unit (15th/median/85th percentiles, $3 / 7 / 23$ vs $2 /$ $5 / 21$ days; $P=.16)$ and postoperative lengths of stay (15th/ median/85th percentiles, $10 / 19 / 57$ vs $8 / 15 / 31$ days; $P=.2$ ). BAR patients required more reoperations for bleeding (10 [37\%] vs $5[9.3 \%] ; P=.002)$, but with no difference in need for transfusion $(P=.6)$. After transplant, 9 BAR and 10 non-BAR patients required tracheostomy. These were performed between days 8 and 40 in the BAR group and between days 3 and 24 in the non-BAR group $(P=.2$, log-rank). Extracorporeal membrane oxygenation was used in 1 BAR patient on posttransplant day 1 and in 4 non-BAR patients, 1 at transplant and 1 on days 1,9 , and 17 ( $P=.7, \log$-rank). The chest needed to be left open, then closed postoperatively, in a similar proportion of patients (2 BAR patients and 4 non-BAR patients, 7.4\% each). One BAR patient (3.7\%) required decortication postoperatively. No sternal wound infections occurred in either group.

\section{Clinical Effectiveness}

Airway ischemia and interventions. One BAR patient experienced airway ischemia issues $(3.7 \%$; CL, $0.6 \%-12 \%)$ compared with 12 non-BAR patients $(22 \%$; CL, $16 \%$ $29 \%)(P=.03$, Fisher exact test; Videos 2 and 3$)$. The airway ischemia in the BAR patient was evident on day 14 . For non-BAR patients, it occurred between day 13 and 7 months posttransplant (Figure 1). No BAR patient had an anastomotic intervention (CL, $0 \%-6.6 \%$ ), whereas 8 nonBAR patients did $(15 \%$; CL, 9.9\%-21\%) $(P=.04$, Fisher exact test). These interventions occurred between day 36 and 9.5 months posttransplant (Figure 2). Three patients required balloon bronchial dilatation only, and 5 required multiple and complex interventions, including airway stenting.

Primary graft dysfunction. Although BAR procedure patients seemed to have higher PGD scores than matched 
TABLE 1. Characteristics of BAR and non-BAR 1:2 matched patients

\begin{tabular}{|c|c|c|c|c|c|c|c|}
\hline \multirow[b]{2}{*}{ Characteristic } & \multicolumn{3}{|c|}{ BAR $(\mathbf{n}=27)$} & \multicolumn{3}{|c|}{ Non-BAR $(\mathbf{n}=52)$} & \multirow[b]{2}{*}{$\begin{array}{c}P \\
\text { value } \\
\end{array}$} \\
\hline & n* & $\begin{array}{l}\text { No. }(\%) \text { or } \\
\text { mean } \pm \text { SD }\end{array}$ & $\begin{array}{c}\mathbf{1 5 / 5 0 / 8 5} \\
\text { Percentiles }\end{array}$ & $\mathbf{n}^{*}$ & $\begin{array}{l}\text { No. }(\%) \text { or } \\
\text { mean } \pm \text { SD }\end{array}$ & $\begin{array}{c}15 / 50 / 85 \\
\text { Percentiles }\end{array}$ & \\
\hline \multicolumn{8}{|l|}{ Recipient } \\
\hline \multicolumn{8}{|l|}{ Demographics } \\
\hline Age, $y$ & 27 & $50 \pm 13$ & $35 / 52 / 64$ & 54 & $52 \pm 14$ & $37 / 58 / 66$ & .4 \\
\hline Female sex & 27 & $11(41)$ & & 54 & $22(41)$ & & $>.9$ \\
\hline \multicolumn{8}{|l|}{ Primary diagnosis } \\
\hline COPD, emphysema, or $\alpha-1$ antitrypsin disease & 27 & $3(11)$ & & 54 & $6(11)$ & & $>.9$ \\
\hline Cystic fibrosis or bronchiectasis & 27 & $4(15)$ & & 54 & $9(17)$ & & .8 \\
\hline Idiopathic pulmonary fibrosis & 27 & $12(44)$ & & 54 & $27(50)$ & & .6 \\
\hline Pulmonary hypertension & 27 & $2(7.4)$ & & 54 & $3(5.6)$ & & .7 \\
\hline Lymphangiomyomatosis & 27 & $0(0)$ & & 54 & $2(3.7)$ & & $>.9$ \\
\hline Non-transplant-related bronchiolitis obliterans syndrome & 27 & $1(3.7)$ & & 54 & $2(3.7)$ & & $>.9$ \\
\hline Sarcoidosis & 27 & $1(3.7)$ & & 54 & $3(5.6)$ & & .7 \\
\hline Other diagnosis $\dagger$ & 27 & $4(15)$ & & 54 & $2(3.7)$ & & .08 \\
\hline \multicolumn{8}{|l|}{ Comorbidities } \\
\hline Smoking & 27 & $13(48)$ & & 54 & $31(57)$ & & .4 \\
\hline Diabetes & 27 & $4(15)$ & & 54 & $7(13)$ & & .8 \\
\hline Hypertension & 27 & $4(15)$ & & 54 & $7(13)$ & & .8 \\
\hline GERD & 27 & $6(22)$ & & 54 & $13(24)$ & & .8 \\
\hline Serum creatinine, $\mathrm{mg} / \mathrm{dL}$ & 26 & $0.8 \pm 0.19$ & $0.6 / 0.78 / 1$ & 50 & $0.76 \pm 0.23$ & $0.5 / 0.77 / 1$ & .4 \\
\hline \multicolumn{8}{|l|}{ Waiting time and allocation } \\
\hline Time on waiting list, d & 27 & $197 \pm 245$ & $26 / 99 / 475$ & 54 & $208 \pm 256$ & $22 / 91 / 475$ & .9 \\
\hline Lung allocation score & 27 & $46 \pm 16$ & $33 / 43 / 59$ & 54 & $44 \pm 14$ & $34 / 39 / 51$ & .6 \\
\hline \multicolumn{8}{|l|}{ Pulmonary artery pressures, $\mathrm{mmHg}$} \\
\hline Systolic & 14 & $41 \pm 20$ & $24 / 38 / 69$ & 25 & $44 \pm 15$ & $32 / 42 / 55$ & .4 \\
\hline Diastolic & 14 & $18 \pm 10$ & $6.8 / 16 / 32$ & 25 & $18 \pm 10$ & $9.7 / 17 / 24$ & .8 \\
\hline Mean & 14 & $26 \pm 13$ & $13 / 23 / 45$ & 25 & $27 \pm 11$ & $16 / 25 / 34$ & .7 \\
\hline Double-lung transplant & 27 & $20(74)$ & & 54 & $37(69)$ & & 6 \\
\hline \multicolumn{8}{|l|}{ Donor } \\
\hline \multicolumn{8}{|l|}{ Demographics } \\
\hline Age, $y$ & 27 & $35 \pm 14$ & $19 / 36 / 50$ & 54 & $39 \pm 15$ & $19 / 43 / 55$ & .3 \\
\hline \multicolumn{8}{|l|}{ Cause of death } \\
\hline Anoxia & 27 & $4(15)$ & & 54 & $13(24)$ & & .3 \\
\hline Cerebrovascular & 27 & $9(33)$ & & 54 & $16(30)$ & & .7 \\
\hline Head trauma & 27 & $11(41)$ & & 54 & $20(37)$ & & .8 \\
\hline Other & 27 & $3(11)$ & & 54 & $4(7.4)$ & & .6 \\
\hline \multicolumn{8}{|l|}{ Recipient-donor matching } \\
\hline Sex mismatch & 27 & $4(15)$ & & 54 & $21(39)$ & & .03 \\
\hline
\end{tabular}

$B A R$, Bronchial artery revascularization; $C O P D$, chronic obstructive pulmonary disease; GERD, gastroesophageal reflux disease. $*$ Patients with data available. $\dagger$ For BAR: 2 eosinophilic granulomas, 1 mixed connective tissue disease, and 1 Sjogren syndrome. For non-BAR: 1 mixed connective tissue disease and 1 bronchoalveolar carcinoma

non-BAR patients, the difference was not statistically significant $(P \geq .4$, Figure 3$)$.

Rejection. During the first 3 months after lung transplant, freedom from rejection (prevalence of grade A0) was higher in BAR than non-BAR patients (average, $77 \%$ vs $57 \%$; $P=$.008) (Figure 4 and Figure E3 for other grades). Thereafter, distribution of biopsy tissue grades was similar $(P \geq .7)$. Infection. Within the first year after transplantation, pulmonary infection occurred in 7 BAR patients and 42 non-BAR patients (Figure 5), such that by 1 year after $\mathrm{BAR}$, the estimated event number per 100 patients was 30 , and after non-BAR, it was $58(P<.04)$. Bloodstream infections occurred in 2 BAR and 19 non-BAR patients
(Figure E4 and Table E2). There were no sternal wound infections.

Lung function. In both BAR and non-BAR groups, average FEV $1 \%$ plateaued at 6 months posttransplant. Values were similar at that time $(68 \%$ for BAR and $72 \%$ for non-BAR patients; $P>.2$ ) (Figure 6). By last follow-up, 3 BAR and 9 non-BAR patients had developed pre-BOS or BOS. Among BAR patients, BOS grade was pre-BOS in 2 and grade 3 in 1 ; among non-BAR patients, 5 had pre-BOS and 1 had grade 1, 2 had grade 2, and 1 had grade 3. Freedom from BOS at 24 months after transplant was $92 \%$ among BAR patients and 58\% among non-BAR patients (Figure 7). Because of distribution of events after 


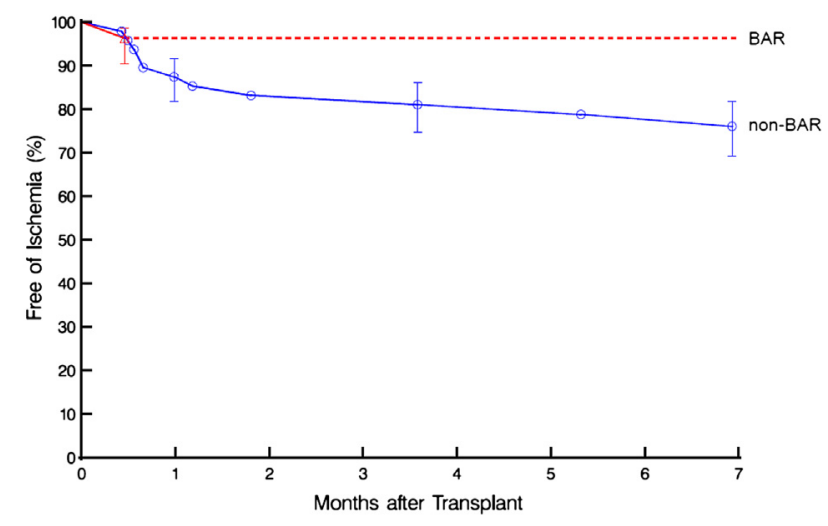

$\begin{array}{llllllll}\text { No. at risk } & & & & & & \\ \text { BAR } & 27 & 26 & 26 & 26 & 25 & 25 & 23 \\ \text { Non-BAR } & 54 & 45 & 43 & 43 & 42 & 42 & 39\end{array}$

FIGURE 1. Freedom from airway ischemia stratified by bronchial artery revascularization $(B A R)$ and non-BAR (propensity-matched patients). Symbols are nonparametric estimates, and vertical bars are $68 \%$ confidence limits equivalent to $\pm 1 \mathrm{SE}$. Numbers in parentheses are patients remaining at risk. The dashed line for the BAR group indicates absence of events beyond the first one.

1 year, and differing assumptions of statistical tests, the $P$ value favoring BAR ranged from .07 (Wilcoxon test) to .14 (log-rank test).

Survival. To date, 4 deaths have occurred among BAR patients, at 1.5 months and $1.7,1.8$, and 2.2 years; 8 deaths have occurred among non-BAR patients between day 1 and 2.1 years posttransplant. Nonparametric survival estimates at 1,3 , and 6 months and 1 and 2 years were $100 \%, 96 \%, 96 \%, 96 \%$, and $83 \%$ for BAR patients and $96 \%, 96 \%, 93 \%, 90 \%$, and $80 \%$ for non-BAR patients, respectively $(P=.6, \log$-rank) (Figure 8$)$. Causes of death are listed in Table 2.

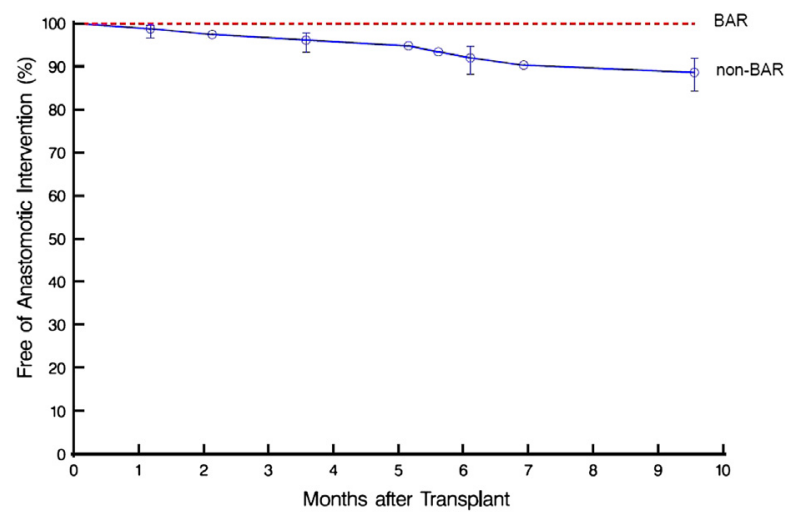

$\begin{array}{llllllll}\text { No. at risk } & & & & & & & \\ \text { BAR } & 27 & 27 & 27 & 26 & 24 & 19 & 19 \\ \text { Non-BAR } & 54 & 54 & 51 & 49 & 45 & 36 & 35\end{array}$

FIGURE 2. Freedom from posttransplant anastomotic intervention for propensity-matched bronchial artery revascularization $(B A R)$ and nonBAR patients. There were no such interventions in BAR patients. Depiction is as in Figure 1.

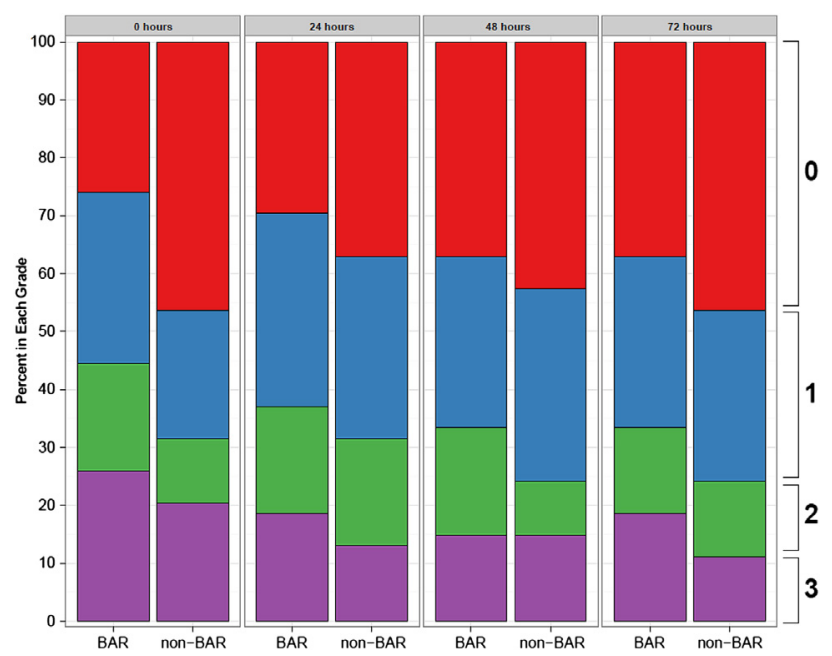

FIGURE 3. Stacked bar graph of primary graft dysfunction grades 0 to 3 at $0,24,48$, and 72 hours after lung transplant for bronchial artery revascularization $(B A R)$ and propensity-matched non-BAR patients.

\section{DISCUSSION}

New evidence shows that ischemia is important in the pathogenesis of airway fibrosis, a key element responsible for $\mathrm{OB}$, causing progressive loss of function (BOS) and death in many patients after lung transplantation. ${ }^{2}$ Although cutting back and anastomosing the donor bronchus at the secondary carina may reduce anastomotic complications and need for interventions, it does not alter distal airway and lung tissue ischemia resulting from ignoring bronchial artery circulation. ${ }^{26,27}$ Successful BAR should consistently provide a normal nonischemic airway (Videos 2 and 3).

The Copenhagen series showed high procedural success, safety, and excellent long-term outcomes after BAR. ${ }^{7}$ In the absence of other larger series, however, this single series

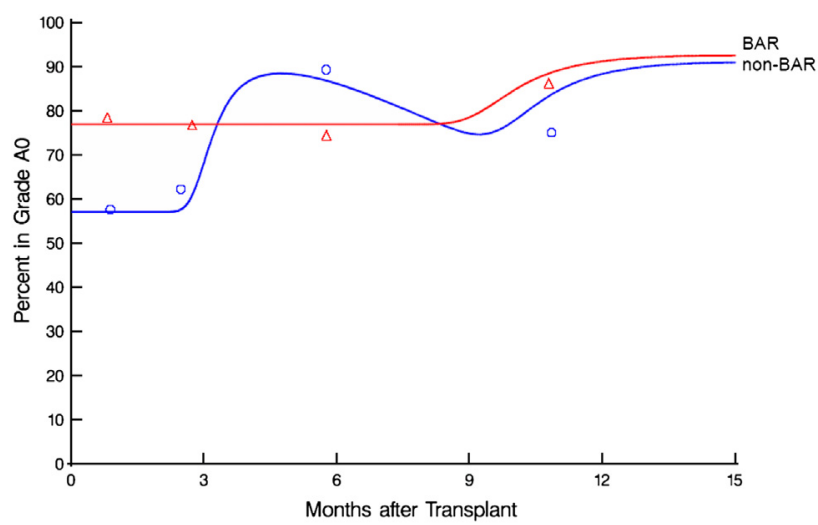

FIGURE 4. Proportion of patients in vascular rejection grade 0 after lung transplantation, according to whether bronchial artery revascularization $(B A R)$ was performed (propensity-matched patients). Symbols are actual grouped data, without regard to repeated measurements, used as a crude verification of the model. 


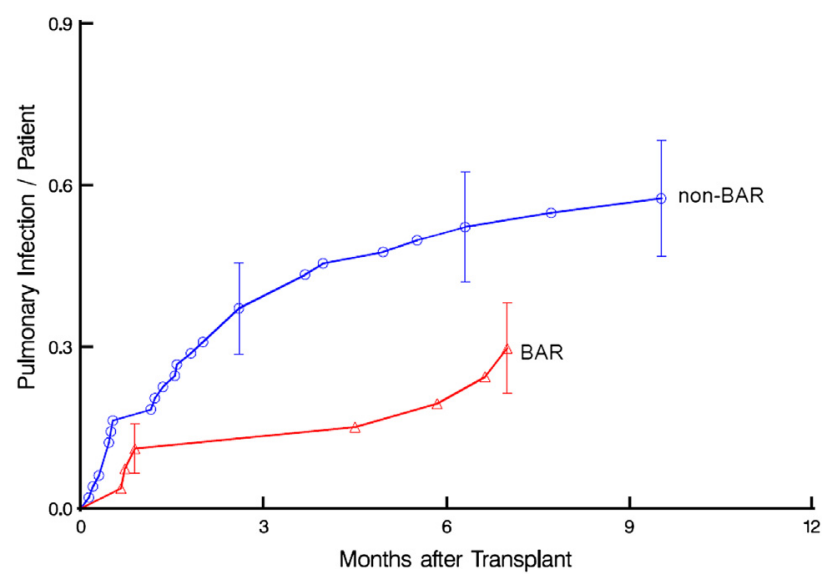

FIGURE 5. Cumulative incidence of pulmonary infections during the first year after transplantation among propensity-matched bronchial artery revascularization $(B A R)$ and non-BAR patients. Depiction is as in Figure 1, except that the vertical axis is cumulative incidence, and number of patients remaining at risk is greater because patients remain at risk of infections.

was insufficient to convince the lung transplant community that BAR was worthwhile, given the added complexity of both harvesting and transplantation. The Cleveland Clinic pilot study has so far confirmed feasibility with high procedural success, as evidenced by angiographic patency of the internal thoracic artery and perfusion of the airway, relative safety, and clinical effectiveness. Because of small numbers, we did not attempt to associate outcomes with grade of angiographic success of BAR.

The present study represents a first attempt to compare outcomes after lung transplantation with and without BAR in matched patients. BAR was associated with less airway ischemia, did not require airway interventions, and had otherwise comparable safety, except for a higher risk of reoperation for bleeding, which exceeded that observed in the Copenhagen series. A new, possibly important, finding in this comparison study was that BAR patients had less early

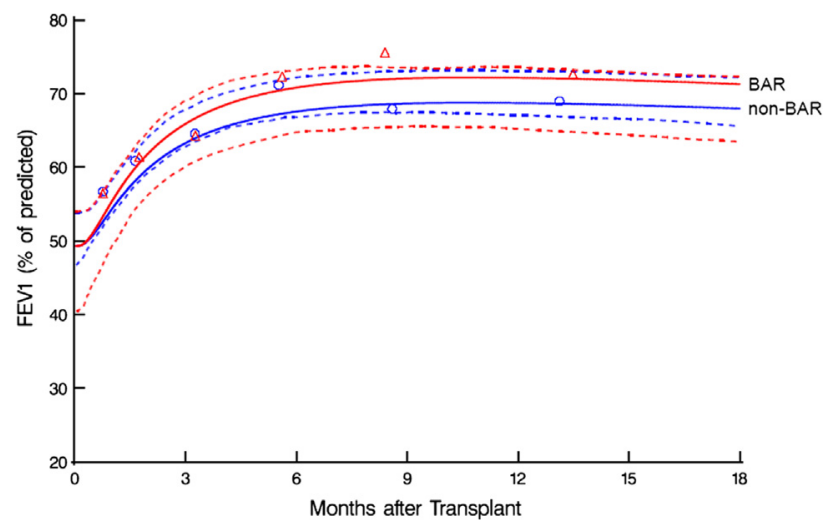

FIGURE 6. Estimated mean forced 1-second expiratory volume (FEV1) after lung transplant, stratified by bronchial artery revascularization $(B A R)$ and propensity-matched non-BAR patients. Format is as in Figure 4.

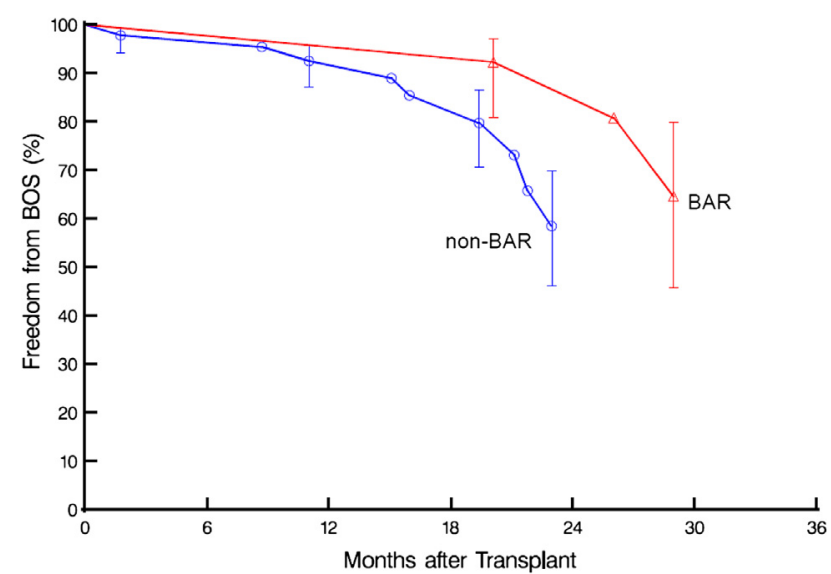

FIGURE 7. Freedom from bronchiolitis obliterans syndrome (BOS) after lung transplant for bronchial artery revascularization $(B A R)$ and propensity-matched non-BAR patients. Depiction is as in Figure 1.

evidence of rejection. This adds an immunologic mechanism to the apparent airway ischemia and other factors contributing to development of airway fibrosis, BOS, and OB. Altered antigen presentation and immunologic response may both be secondary to ischemia.

A second new finding was substantially fewer pulmonary and bloodstream infections after transplantation with BAR. We speculate that this finding may be related, in part, to bronchial blood flow with a healthier airway. In addition, in BAR patients, there was less opportunity for bacterial colonization, which is likely increased in those requiring interventions and stents and in those who have ischemic, necrotic, dehisced, or stenotic segments of their airway. A third finding is possibly somewhat delayed development of BOS, in accordance with a Copenhagen finding, ${ }^{28}$ which may relate to the combined effect of reduced bronchial ischemia, lower-grade rejections, and fewer infections.

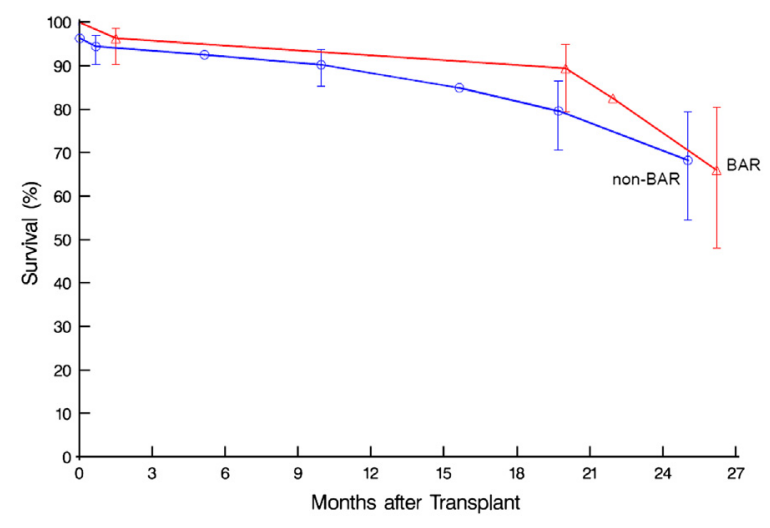

$\begin{array}{llllllll}\text { No. at risk } & & & & & & \\ \text { BAR } & 27 & 26 & 26 & 26 & 26 & 13 & 5 \\ \text { Non-BAR } & 54 & 52 & 50 & 40 & 17 & 16 & 7\end{array}$

FIGURE 8. Survival after lung transplant for bronchial artery revascularization $(B A R)$ and propensity-matched non-BAR patients. Depiction is as in Figure 1. 
TABLE 2. Cause of death in matched patients after BAR and nonBAR lung transplantation

\begin{tabular}{lcc}
\hline \multicolumn{1}{c}{ Cause } & BAR $(\mathbf{n}=\mathbf{4})$ & Non-BAR $(\mathbf{n}=\mathbf{8})$ \\
\hline Cerebral & $0(0)$ & $2(25)$ \\
Infection & $0(0)$ & $1(12)$ \\
Malignancy & $1(25)$ & $2(25)$ \\
Organ failure & $1(25)$ & $1(12)$ \\
Brainstem herniation & $1(25)$ & $0(0)$ \\
Respiratory failure & $1(25)$ & $1(12)$ \\
Hemorrhage (nonstroke) & $0(0)$ & $1(12)$ \\
\hline
\end{tabular}

Data are given as number (percentage) of patients. $B A R$, Bronchial artery revascularization.

\section{Limitations}

This is a single-center study performed as part of an ongoing pilot study of restarting a BAR program after the success of the Copenhagen experience. It reflects specific restrictions imposed by the IRB, including its nonrandomized nature. To compensate for this, we have performed a propensity-matched BAR versus non-BAR study.

Technical difficulty remains an obstacle to wider acceptance of BAR. This obstacle is related to the fact that most lung transplant surgeons are general thoracic surgeons not used to performing internal thoracic artery anastomoses daily. BAR patients required more reoperations for bleeding early in the series, often because of the BAR anastomosis. Anastomosing the internal thoracic artery to the aortic ostia of the bronchial arteries is different from coronary anastomosis and requires practice. This highlights the importance of the second half of our pilot study, which is to study teachability of BAR.

\section{CONCLUSIONS}

Although associated with an elevated risk of reoperation for bleeding, BAR can be performed successfully and relatively safely and is associated with reduced airway ischemia, less early rejection, and fewer pulmonary infections compared with when bronchial artery circulation is ignored. These benefits of BAR are likely to have a long-term effect on late-developing BOS, a trend already observed in this study. These findings are encouraging enough to support a call for a multicenter trial to establish the benefits of BAR.

\section{References}

1. Christie JD, Edwards LB, Kucheryavaya AY, Benden C, Dobbels F, Kirk R, et al. The Registry of the International Society for Heart and Lung Transplantation: Twenty-eighth Adult Lung and Heart-Lung Transplant Report-2011. J Heart Lung Transplant. 2011;30:1104-22.

2. Nicolls MR, Zamora MR. Bronchial blood supply after lung transplantation without bronchial artery revascularization. Curr Opin Organ Transplant. 2010; 15:563-7.

3. Couraud L, Baudet E, Martigne C, Roques X, Velly JF, Laborde N, et al., Bordeaux Lung and Heart-Lung Transplant Group. Bronchial revascularization in doublelung transplantation: a series of 8 patients. Ann Thorac Surg. 1992;53:88-94.

4. Daly RC, McGregor CG. Routine immediate direct bronchial artery revascularization for single-lung transplantation. Ann Thorac Surg. 1994;57:1446-52.
5. Pettersson G, Arendrup H, Mortensen SA, Aldershvile J, Thiis JJ, Aggestrup S, et al. Early experience of double-lung transplantation with bronchial artery revascularization using mammary artery. Eur J Cardiothorac Surg. 1994;8:520-4.

6. Pettersson G, Norgaard MA, Arendrup H, Brandenhof P, Helvind M, Joyce F, et al. Direct bronchial artery revascularization and en bloc double lung transplantation: surgical techniques and early outcome. J Heart Lung Transplant. 1997;16: 320-33.

7. Burton CM, Milman N, Carlsen J, Arendrup H, Eliasen K, Andersen CB, et al. Copenhagen National Lung Transplant Group. Survival after single lung, double lung, and heart-lung transplantation. J Heart Lung Transplant. 2005;24:1834-43.

8. Rubin DB. The design versus the analysis of observational studies for causal effects: parallels with the design of randomized trials. Stat Med. 2007;26:20-36.

9. Schreinemakers HH, Weder W, Miyoshi S, Harper BD, Shimokawa S, Egan TM, et al. Direct revascularization of bronchial arteries for lung transplantation: an anatomical study. Ann Thorac Surg. 1990;49:44-53; discussion 54.

10. Laks H, Louie HW, Haas GS, Drinkwater DC Jr, Lewis W, Permut LC, et al. New technique of vascularization of the trachea and bronchus for lung transplantation. J Heart Lung Transplant. 1991;10:280-7.

11. Dubrez J, Clerc F, Drouillard J, Couraud L. Anatomical bases for bronchial arterial revascularization in double lung transplantation [in French]. Ann Chir. 1992; 46:97-104.

12. Couraud L, Baudet E, Nashef SA, Martigne C, Roques X, Velly JF, et al. Lung transplantation with bronchial revascularisation: surgical anatomy, operative technique and early results. Eur J Cardiothorac Surg. 1992;6:490-5.

13. Svendsen U, Arendrup H, Norgaard M, Olsen P, Thiis J, Mortensen S, et al. Double lung transplantation with bronchial artery revascularization using mammary artery. Transplant Proc. 1995;27:3485.

14. Norgaard MA, Olsen PS, Svendsen UG, Pettersson G. Revascularization of the bronchial arteries in lung transplantation: an overview. Ann Thorac Surg. 1996;62:1215-21.

15. Pettersson GB, Norgaard MA, Andersen CB, Arendrup H, Efsen F, Mortensen SA, et al. Lung and Heart-Lung Transplantation With Direct Bronchial Artery Revascularization. Darmstadt, Germany: Steinkopff Darmstadt; 1999.

16. Hyytinen TA, Keto PE, Heikkila LJ, Verkkala KA, Sipponen JT, Mattila SP, et al. Magnetic resonance imaging angiography in patency evaluation of bronchial artery revascularization grafts. Scand Cardiovasc J. 2000;34:421-5.

17. Yousem SA, Berry GJ, Cagle PT, Chamberlain D, Husain AN, Hruban RH, et al., Lung Rejection Study Group. Revision of the 1990 working formulation for the classification of pulmonary allograft rejection. J Heart Lung Transplant. 1996; 15:1-15.

18. Christie JD, Carby M, Bag R, Corris P, Hertz M, Weill D. Report of the ISHLT Working Group on Primary Lung Graft Dysfunction part II: definition: a consensus statement of the International Society for Heart and Lung Transplantation. J Heart Lung Transplant. 2005;24:1454-9.

19. American Thoracic Society. Standardization of spirometry, 1994 update. Am J Respir Crit Care Med. 1995;152:1107-36.

20. Hankinson JL, Odencrantz JR, Fedan KB. Spirometric reference values from a sample of the general US population. Am J Respir Crit Care Med. 1999;159: 179-87.

21. Cooper JD, Billingham M, Egan T, Hertz MI, Higenbottam T, Lynch J, et al., International Society for Heart and Lung Transplantation. A working formulation for the standardization of nomenclature and for clinical staging of chronic dysfunction in lung allografts. J Heart Lung Transplant. 1993;12:713-6.

22. Breiman L. Bagging predictors. Machine Learning. 1996;24:123-40.

23. Blackstone EH. Comparing apples and oranges. J Thorac Cardiovasc Surg. 2002; 123:8-15.

24. Gillinov AM, Bhavani S, Blackstone EH, Rajeswaran J, Svensson LG, Navia JL, et al. Surgery for permanent atrial fibrillation: impact of patient factors and lesion set. Ann Thorac Surg. 2006;82:502-14.

25. Nelson W. Applied Life Data Analysis. New York, NY: John Wiley; 1982.

26. Inci I, Stanimirov O, Benden C, Kestenholz P, Hofer M, Boehler A, et al. Lung transplantation for cystic fibrosis: a single center experience of 100 consecutive cases. Eur J Cardiothorac Surg. 2012;41:435-40.

27. van Berkel V, Guthrie TJ, Puri V, Krupnick AS, Kreisel D, Patterson GA, et al. Impact of anastomotic techniques on airway complications after lung transplant. Ann Thorac Surg. 2011;92:316-20; discussion 20-1.

28. Norgaard MA, Andersen CB, Pettersson G. Does bronchial artery revascularization influence results concerning bronchiolitis obliterans syndrome and/or obliterative bronchiolitis after lung transplantation? Eur J Cardiothorac Surg. 1998; 14:311-8. 
APPENDIX E1. Variables Considered in All Multivariable Analyses

\section{Recipient}

Demographics: Age $(\mathrm{y})^{*}$, sex*, weight $(\mathrm{kg})$, height $(\mathrm{cm})$, body mass index $\left(\mathrm{kg} \cdot \mathrm{m}^{2}\right)$, body surface area $\left(\mathrm{m}^{2}\right)$, weight-height ratio, race

Diagnosis: Chronic obstructive pulmonary disease, emphysema, or $\alpha-1$ antitrypsin disease*; cystic fibrosis or bronchiectasis*; idiopathic pulmonary fibrosis*; pulmonary hypertension; sarcoidosis

Comorbidities: Smoking*, diabetes*, gastroesophageal reflux disease*, hypertension, serum creatinine $(\mathrm{mg} / \mathrm{dL})$, total bilirubin $(\mathrm{mg} / \mathrm{dL})$, hematocrit $(\%)$, blood urea nitrogen $(\mathrm{mg} / \mathrm{dL})$, creatinine clearance, glomerular filtration rate, total protein $(\mathrm{mg} / \mathrm{dL})$

Waiting time and allocation: Days on waiting list*, lung allocation score*

Systemic pressures (mmHg): Systolic*, diastolic*, mean

Blood type: A/A1/A2, AB, B, O

Surgical: Cardiopulmonary bypass time (min), double or single lung transplant*, ischemic time ( $\mathrm{min})$

Donor

Demographics: Age (y), sex, weight $(\mathrm{kg})$, height $(\mathrm{cm})$, body mass index $\left(\mathrm{kg} \cdot \mathrm{m}^{2}\right)$, body surface area $\left(\mathrm{m}^{2}\right)$, weight-height ratio, race

Comorbidities: Smoker, serum creatinine (mg/dL), total bilirubin ( $\mathrm{mg} / \mathrm{dL}$ ), blood urea nitrogen $(\mathrm{mg} / \mathrm{dL})$

Blood type: A/A1/A2, AB, B, O

Cause of death: Anoxia, cerebrovascular, head trauma

Recipients + Donor

Race mismatch, sex mismatch, weight ratio

*Variables in propensity model.
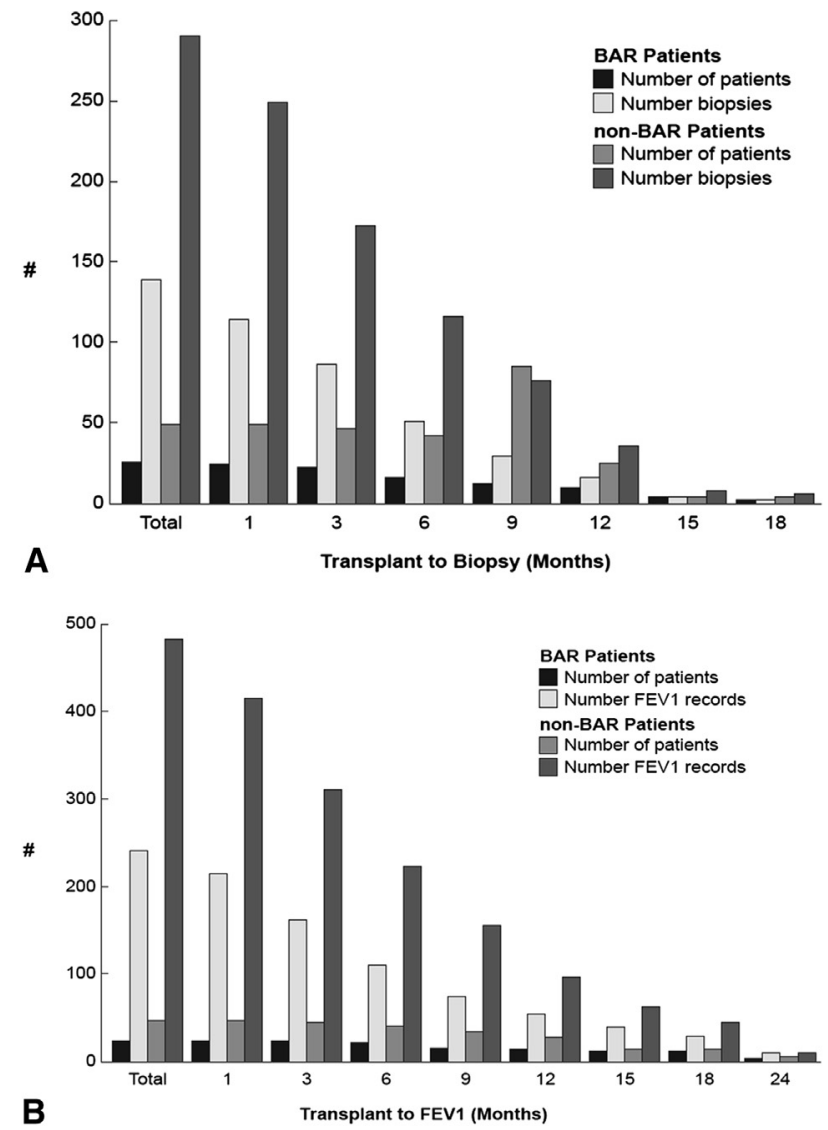

FIGURE E1. Number of test results available across time for bronchial artery revascularization $(B A R)$ and propensity-matched non-BAR patients. A, Lung biopsy specimens. B, Pulmonary function test results. 

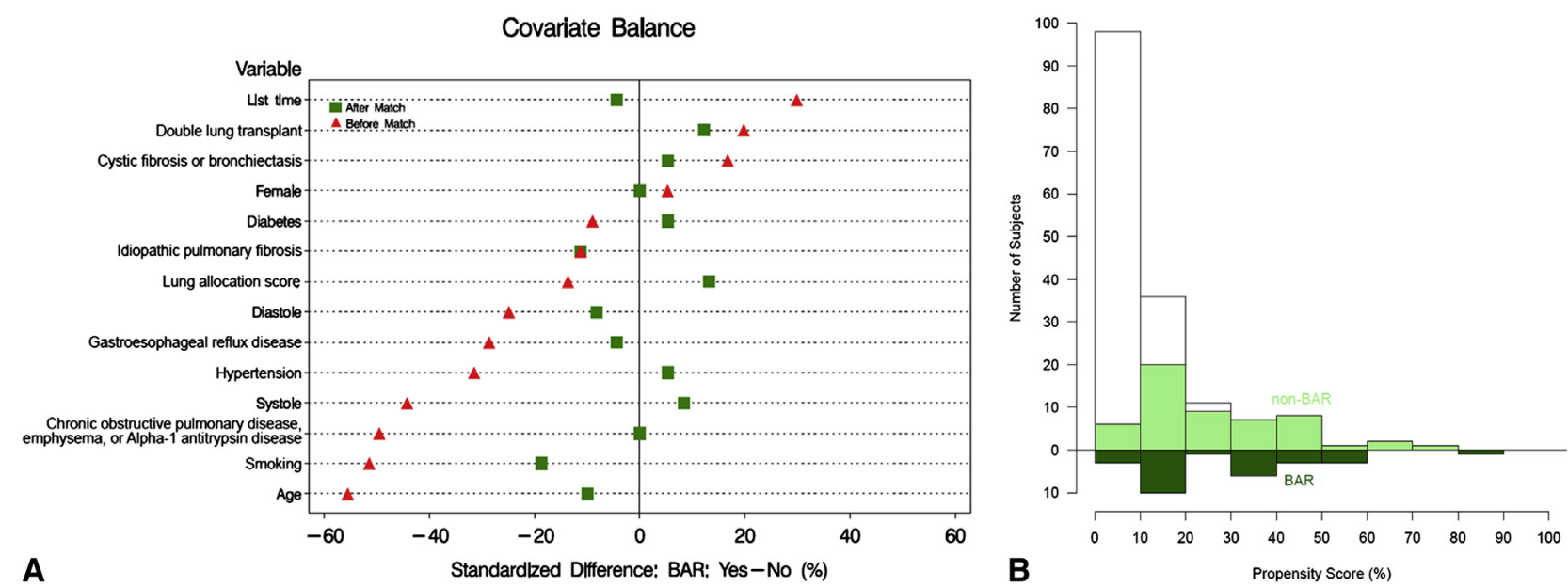

FIGURE E2. Quality and extent of propensity-based matching. A, Covariate balance description before (red triangles) and after (green squares) matching between bronchial artery revascularization $(B A R)$ and non-BAR groups. B, Mirrored histogram of distribution of propensity scores for BAR versus non-BAR groups. Light and dark green areas represent matched patient pairs.

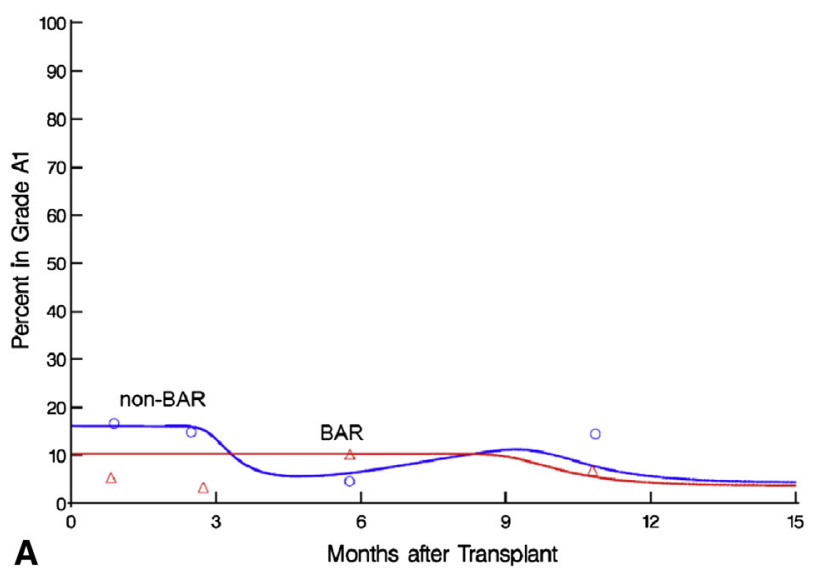

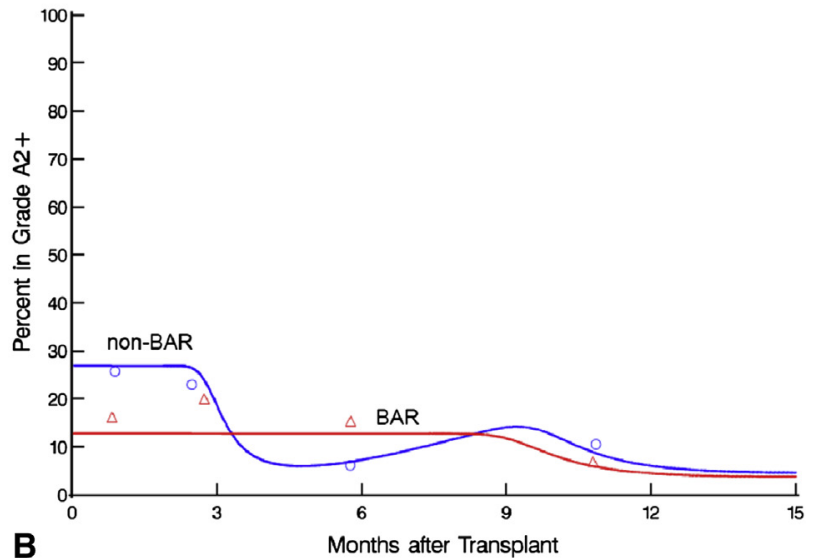

FIGURE E3. Proportion of patients in vascular rejection grades other than 0 after lung transplantation, according to whether bronchial artery revascularization $(B A R)$ was performed (propensity-matched patients). Symbols are actual grouped data, without regard to repeated measurements, used as a crude verification of the model. A, Grade A1. B, Grade A2 or higher.

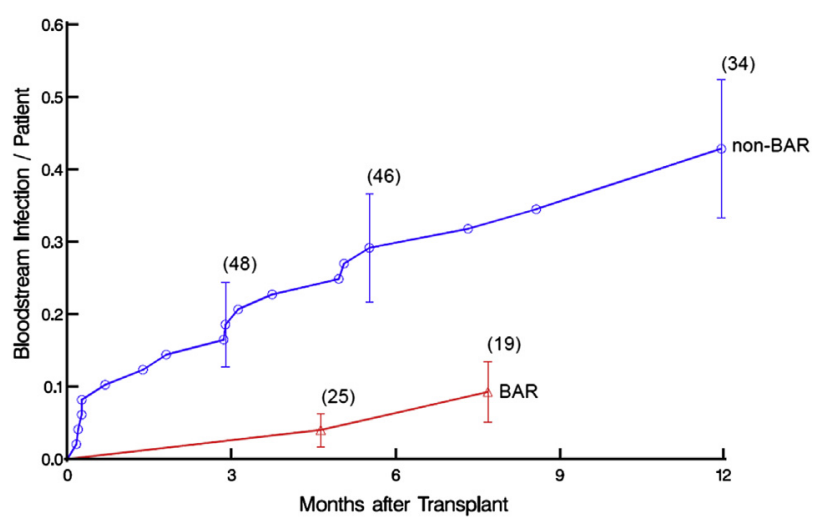

FIGURE E4. Cumulative incidence of bloodstream infections during the first year after transplantation. Patients are stratified according to whether bronchial artery revascularization (BAR) was performed (propensitymatched patients). Each symbol represents an event; vertical bars, $68 \%$ confidence limits of nonparametric estimates equivalent to $\pm 1 \mathrm{SE}$; and numbers in parentheses, patients remaining at risk. 
TABLE E1. Characteristics of all recipients and donors, stratified by BAR and non-BAR

\begin{tabular}{|c|c|c|c|c|c|c|c|}
\hline \multirow[b]{2}{*}{ Characteristic } & \multicolumn{3}{|c|}{ BAR $(\mathbf{n}=27)$} & \multicolumn{3}{|c|}{ Non-BAR $(n=160)$} & \multirow[b]{2}{*}{$\begin{array}{c}P \\
\text { value }\end{array}$} \\
\hline & $\mathbf{n}^{*}$ & $\begin{array}{l}\text { No. }(\%) \text { or } \\
\text { mean } \pm \text { SD }\end{array}$ & $\begin{array}{c}15 / 50 / 85 \\
\text { Percentiles }\end{array}$ & $\mathbf{n}^{*}$ & $\begin{array}{l}\text { No. }(\%) \text { or } \\
\text { mean } \pm \text { SD }\end{array}$ & $\begin{array}{c}\mathbf{1 5 / 5 0 / 8 5} \\
\text { Percentiles }\end{array}$ & \\
\hline \multicolumn{8}{|l|}{ Recipient } \\
\hline \multicolumn{8}{|l|}{ Demographics } \\
\hline Age, y & 27 & $50 \pm 13$ & $35 / 52 / 64$ & 160 & $57 \pm 12$ & $46 / 61 / 67$ & .004 \\
\hline Female sex & 27 & $11(41)$ & & 160 & $61(38)$ & & .8 \\
\hline \multicolumn{8}{|l|}{ Primary diagnosis } \\
\hline COPD, emphysema, or $\alpha-1$ antitrypsin disease & 27 & $3(11)$ & & 160 & $49(31)$ & & .04 \\
\hline Cystic fibrosis or bronchiectasis & 27 & $4(15)$ & & 160 & $15(9.4)$ & & .4 \\
\hline Idiopathic pulmonary fibrosis & 27 & $12(44)$ & & 160 & $80(50)$ & & 6 \\
\hline Pulmonary hypertension & 27 & $2(7.4)$ & & 160 & $4(2.5)$ & & .2 \\
\hline Lymphangiomyomatosis & 27 & $0(0)$ & & 160 & $1(0.6)$ & & $>.9$ \\
\hline Non-transplant-related bronchiolitis obliterans syndrome & 27 & $1(3.7)$ & & 160 & $2(1.3)$ & & $>.9$ \\
\hline Sarcoidosis & 27 & $1(3.7)$ & & 160 & $5(3.1)$ & & .7 \\
\hline Other diagnosis $\dagger$ & 27 & $4(15)$ & & 160 & $3(1.9)$ & & .08 \\
\hline \multicolumn{8}{|l|}{ Comorbidities } \\
\hline Smoking & 27 & $13(48)$ & & 160 & $116(73)$ & & .01 \\
\hline Diabetes & 27 & $4(15)$ & & 160 & $29(18)$ & & .7 \\
\hline Hypertension & 27 & $4(15)$ & & 160 & $44(28)$ & & .2 \\
\hline GERD & 27 & $6(22)$ & & 160 & $56(35)$ & & .2 \\
\hline Serum creatinine, $\mathrm{mg} / \mathrm{dL}$ & 26 & $0.8 \pm 0.19$ & $0.6 / 0.78 / 1$ & 149 & $0.79 \pm 0.21$ & $0.55 / 0.78 / 1.0$ & .8 \\
\hline \multicolumn{8}{|l|}{ Waiting time and allocation } \\
\hline Time on waiting list, $\mathrm{d}$ & 27 & $197 \pm 245$ & $26 / 99 / 475$ & 160 & $127 \pm 219$ & $7 / 37 / 230$ & .006 \\
\hline Lung allocation score & 27 & $46 \pm 16$ & $33 / 43 / 59$ & 160 & $48 \pm 19$ & $33 / 39 / 77$ & .8 \\
\hline \multicolumn{8}{|l|}{ Pulmonary artery pressures, $\mathrm{mmHg}$} \\
\hline Systolic & 14 & $41 \pm 20$ & $24 / 38 / 69$ & 84 & $44 \pm 16$ & $32 / 40 / 60$ & .3 \\
\hline Diastolic & 14 & $18 \pm 10$ & $6.8 / 16 / 32$ & 84 & $19 \pm 9.2$ & $11 / 18 / 26$ & .5 \\
\hline Mean & 14 & $26 \pm 13$ & $13 / 23 / 45$ & 84 & $28 \pm 11$ & $17 / 26 / 37$ & .5 \\
\hline Double-lung transplant & 27 & $20(74)$ & & 160 & $104(65)$ & & .4 \\
\hline \multicolumn{8}{|l|}{ Donor } \\
\hline \multicolumn{8}{|l|}{ Demographics } \\
\hline Age, y & 27 & $35 \pm 14$ & $19 / 36 / 50$ & 159 & $39 \pm 16$ & $20 / 42 / 56$ & .2 \\
\hline \multicolumn{8}{|l|}{ Cause of death } \\
\hline Anoxia & 27 & $4(15)$ & & 160 & $29(18)$ & & .7 \\
\hline Cerebrovascular & 27 & $9(33)$ & & 160 & $59(37)$ & & .7 \\
\hline Head trauma & 27 & $11(41)$ & & 160 & $60(38)$ & & .8 \\
\hline Other & 27 & $3(11)$ & & 160 & $11(6.9)$ & & .4 \\
\hline \multicolumn{8}{|l|}{ Recipient-donor matching } \\
\hline Sex mismatch & 27 & $4(15)$ & & 160 & $47(29)$ & & .12 \\
\hline
\end{tabular}

TABLE E2. Bronchial infections within the first year after lung transplantation for 1:2 propensity-matched BAR and non-BAR patients

\begin{tabular}{lcc}
\hline \multicolumn{1}{c}{ Infection site } & BAR & Non-BAR \\
\hline Pulmonary & 7 & 34 \\
Pleural & 1 & 2 \\
Bloodstream & 2 & 19 \\
Gastrointestinal tract & 2 & 7 \\
Urinary tract & 2 & 4 \\
Surgical site & 3 & 2 \\
\hline
\end{tabular}

$B A R$, Bronchial artery revascularization. 